\title{
Pandemic medical ethics
}

Jennifer Blumenthal-Barby, ${ }_{1}^{1}$ Kenneth Boyd ${ }_{1}{ }^{2}$ Brian D Earp, ${ }^{3}$

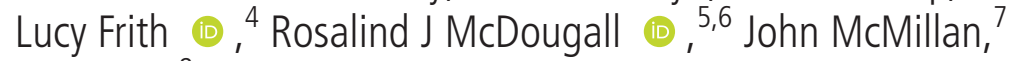
Jesse Wall ${ }^{8}$

The COVID-19 pandemic will generate vexing ethical issues for the foreseeable future and many journals will be open to content that is relevant to our collective effort to meet this challenge. While the pandemic is clearly the critical issue of the moment, it's important that other issues in medical ethics continue to be addressed as well. As can be seen in this issue, the Journal of Medical Ethics (JME) will uphold its commitment to publishing high quality papers on the full array of medical ethics.

At the same time, JME aims to be a premiere home for ground-breaking scholarship on the ethical issues raised by COVID-19. Toward this end, we have a number of papers that are freely available online and for which production has been fast-tracked. ${ }^{1-5}$ A challenge for authors who want to write about the pandemic is the rapidly evolving nature of the situation and the time it takes for journal content to be reviewed and published, even when fast-tracked. For that reason, all authors who would like to submit a paper on the pandemic can also submit a post to the JME blog prior to submitting a full paper to the journal. Those interested in writing for the JME blog should contact one of its editors, Hazem Zohny or Mike King. Over the last 3 weeks, 30 high-quality commentaries on the pandemic have been posted to the blog. These posts are circulated widely via the JME Twitter and Facebook feeds and have stimulated significant interest. The most accessed post is

\footnotetext{
${ }^{1}$ Center for Medical Ethics and Health Policy, Baylor College of Medicine, Houston, Texas, USA

${ }^{2}$ Biomedical Teaching Organisation, Edinburgh University, Edinburgh, UK

${ }^{3}$ Uehiro Centre for Practical Ethics, University of Oxford, Oxford, UK

${ }^{4}$ Health Services Research, University of Liverpool, Liverpool, UK

${ }^{5}$ Centre for Health Equity, Melbourne School of

Population and Global Health, University of Melbourne, Melbourne, Victoria, Australia

${ }^{6}$ Children's Bioethics Centre, Royal Children's Hospital, Melbourne, Victoria, Australia

${ }^{7}$ Bioethics Centre, University of Otago, Dunedin, New Zealand

${ }^{8}$ Faculty of Law, University of Auckland, Auckland, New Zealand
}

Correspondence to Professor John McMillan, Bioethics Centre, University of Otago, Dunedin 9054, New Zealand; john.r.mcmillan68@gmail.com by Udo Schuklenk on the duty of healthcare professionals to care for those with COVID 19 which has been read more than 50000 times.

JME is a forum for the best and most carefully reasoned discussions of ethical issues in medicine and related areas. It emphasises scholarship that seeks to be practically normative and clinically relevant. ${ }^{6}$ What that means for work on the COVID-19 pandemic is worth exploring and we would like to explain how the editorial team will interpret this remit over the coming week and months. This is to give authors and readers a steer about the content we think is particularly important for JME to publish: content that can make a vital contribution to 'live' debates surrounding the many ethical issues and dilemmas that COVID-19 has raised, both for individuals and societies.

Debate in medical ethics needs to be pastorally responsive but also philosophically robust: it might bring 'ethical comfort' or express solidarity with challenges that those working in healthcare face, but it should also be solid in its argument. Theorists who adopt a more distant philosophical analysis of real-world ethical questions can risk seeming remote to the immediate concerns of practitioners. Likewise, those who merely describe a normatively charged situation without availing themselves of theoretical guardrails risk missing the bigger picture. Therefore, we suggest that philosophers (and others with a propensity toward abstract thinking) should consider collaborating with clinicians and policy-makers, where relevant and appropriate, when planning a submission to JME. Likewise, clinicians (and others with a more concrete approach) should consider collaborating with ethicists and philosophers. This will help ensure that any resulting ideas, frameworks, arguments and recommendations are maximally helpful by being nuanced and in touch with the actual issues we face.

There is a spectrum of work on medical ethics in the COVID-19 pandemic which ranges from the 'ultrapractical' to the 'big picture'. The ultrapractical supports clinicians and policymakers in navigating the ethically complex situations that the pandemic has created. Ultrapractical work requires humility, as is the case for all good clinical ethics. In this type of work, ethical analysis can identify and synthesise high quality relevant ethics research. We 'translate' ethics from the academic literature into tools and frameworks for frontline decision-makers who are both time-poor and stressed. The measure of good ultrapractical work is its applicability and utility for the user, thereby meeting one of JME's aims, which is to be practically normative. Ultrapractical work on the COVID-19 pandemic is likely to draw on the published work of experts in public health and clinical ethics and develop ethics tools for decision-makers at the frontline.

Work more toward the big picture end of the spectrum links the COVID-19 pandemic to broader issues in bioethics. This type of ethics work is more reflective, asking what the pandemic can show us about longstanding areas of challenge and controversy in healthcare. There is a range of areas for which the COVID-19 experience is illuminating: disability, healthcare hierarchies, global equity and equal access to care. Rather than developing a new area of bioethics focused specifically on COVID-19, this type of work puts the pandemic in the broader context of bioethics issues and scholarship.

The editorial team encourages papers that undertake a more thoroughgoing analysis of the broader lessons of the COVID-19 pandemic as well. There have been a lot of 'hot takes' and many of these have been helpful and justified, especially given the fast pace at which events are unfolding. But it is also crucial to step back a bit to consider how medical ethicists, philosophers, political and social scientists, economists, health policy specialists and others, can collaborate to shed light on the wider systemic/structural, political and economic dimensions of this situation. What are we learning about the relationships between poverty, racism, ableism, immigration policy and public health, for example? The differential impact of COVID-19 on race and socio-economic status is important and papers that discuss allocation policies that may prioritise racially or socially disadvantaged groups (in, eg, tie-breaker cases) to account for past and present injustices are welcome.

From a normative and theoretical perspective, how are health and wellbeing understood and promoted in a pandemic emergency? Are questions of mental health, social well-being and the fact that 'home' does not mean 'safe' for many people being given adequate 
consideration? What about people who do not have a home? Do we have our tradeoffs and priorities right?

We would also like to see work on the ethics of public science communication, especially during a public health crisis in the age of social media. How should laypeople decide who, or which institutions, to trust under conditions of uncertainty, or when public officials and experts disagree (or when experts disagree with each other)?

Finally, what does the reality of COVID-19 say about bioethics as a discipline, or the role of bioethicists in society? Why are so many 'pandemic ethics' plans or triage heuristics being suddenly thrown together? Is it a problem that multiple conflicting proposals for how to allocate scarce resources (eg, ventilators) are being published on an almost daily basis? How can we reach a consensus about such questions and should consensus be a goal? What should the role be for bioethicists in this kind of crisis, are we equipped to pass judgment on such high-stakes, real-life normative questions, is there a difference between academic and policy-focused bioethics?

These areas and questions are not exhaustive, as COVID-19 generates a maelstrom of ethical questions that will have an impact on all areas of healthcare and welfare provision. We want to encourage a robust and generative debate on these and related issues.

Twitter Brian D Earp @briandavidearp, Lucy Frith @lucy_frith and Rosalind J McDougall @ethicsros

Funding The authors have not declared a specific grant for this research from any funding agency in the public, commercial or not-for-profit sectors.

Competing interests None declared.

Patient consent for publication Not required.

Provenance and peer review Not commissioned; internally peer reviewed.

(c) Author(s) (or their employer(s)) 2020. No commercial re-use. See rights and permissions. Published by BMJ.

\section{D) Check for updates}

To cite Blumenthal-Barby J, Boyd K, Earp BD, et al. $J$ Med Ethics 2020;46:353-354.

Received 11 May 2020

Accepted 11 May 2020
J Med Ethics 2020;46:353-354.

doi:10.1136/medethics-2020-106431

ORCID iDs

Lucy Frith http://orcid.org/0000-0002-8506-0699 Rosalind J McDougall http://orcid.org/0000-00023809-2575

\section{REFERENCES}

1 Parker MJ, Fraser C, Abeler-Dörner L, et al. Ethics of instantaneous contact tracing using mobile phone apps in the control of the COVID-19 pandemic. J Med Ethics 2020. doi: 10.1136/medethics-2020-106314. [Epub ahead of print 4 May 2020].

2 Parsons JA, Johal HK. Best interests versus resource allocation: could COVID-19 cloud decision-making for the cognitively impaired? J Med Ethics 2020. doi: 10.1136/medethics-2020-106323. [Epub ahead of print 6 May 2020].

3 McConnell D. Balancing the duty to treat with the duty to family in the context of the COVID-19 pandemic. J Med Ethics 2020:46:360-3.

4 Solnica A, Barski L, Jotkowitz A. Allocation of scarce resources during the COVID-19 pandemic: a Jewish ethical perspective. J Med Ethics 2020. doi: 10.1136/ medethics-2020-106242. [Epub ahead of print 10 April 2020].

5 Mannelli C. Whose life to save? Scarce resources allocation in the COVID-19 outbreak. J Med Ethics 2020;46:364-6.

6 McMillan J. Good medical ethics. J Med Ethics 2018;44(8):511-2. 